\title{
Foucault y
}

\section{Jorge Luis Gimerer. la nueva filosofía del poder}

No hay libro que se parezca más a la Genealogía de la moral de Nietzsche, que Vigilar y castigar de Michel Foucault. Además de los testimonios que el mismo Foucault nos brinda con respecto a esta evidente continuidad temática entre una y otra obra, con la idea de una Genealogía del alma moderna, su autor parece sugerirnos no solo la necesidad de rendir tributo al engarce y vertebración de los fenómenos epocales entre sí como a sus rupturas, imantaciones e infiltraciones, sino también a considerar el verdadero rol de sus positividades, vale decir, cierto grado de objetividad que termina por divorciarse de la vida al provocar la articulación de todo lo real en un efecto de conjunto.

Vistos y expuestos estos propósitos que indudablemente merecen nuestra atención, entre la genealogía nietzscheana y la teoría del poder de Foucault existen muchas más relaciones, además de las vinculaciones temáticas ya mencionadas, que difieren entre sí a tal punto de volverse tremendamente valioso el partir por observarlas para intentar pensar sus lugares comunes.

Comencemos por algunas de ellas: La genealogía de Nietzsche es escandalosa e irreverente por cuanto desenmascara el verdadero origen de la moral, oponiéndose al carácter absoluto de sus principios mediante la afirmación de su verdadera procedencia. En Vigilar y castigar Foucault denuncia la verdadera causa de la prisión en la que vive el alma moderna, mostrándonos cómo se ha configurado el poder de castigar, bajo qué condiciones específicas ha devenido hasta hoy un lugar omnisciente y omnipotente, y hasta qué punto su identificación con ese aire de excentricidad y mascarada, con esa apariencia de sistematicidad e inconsecuencia, con ese poder de impacto que sobreviene luego del primer encuentro, no es más que el testimonio de su total vacuidad.

Como decimos, ambas interpretaciones cargadas de esa violencia que fuera de representar el coraje con el que sus autores parecen hacer manifiesta su inconformidad y su irreverencia, representan el distanciamiento que debe experimentar todo genealogista de vocación, puesto que sin él, la interpretación no llegaría a la superación de sí misma, vale decir, a la negación de su procedencia en un más allá de sí misma.

No obstante, este rasgo de la violencia hermenéutica que identifica a ambas obras en cuestión, la genealogía nietzscheana al situar la esencia del poder en el centro de la reflexión, parece asentarse en algo más que en una mera crítica hermenéutica.

Con el postulado de la vida como voluntad de poder, la genealogía de Nietzsche parece instalarse en un lugar que está ausente en la genealogía foucaultiana, por cuanto ésta no distingue la corrección del mundo como vis configuradora de la infinita sed de acrecentamiento que representa la vida. La teoría del poder, frente a la genealogía de la moral, parece ser más crítica hermenéutica que violencia interpretativa, debido a que la hermenéutica del poder al alimentarse de los mecanismos configuradores de las épocas (Época Clásica, Transición y Modernidad), sus continuidades y discontinuidades, vertebraciones y articulaciones, da, por esto, más relevancia al encuentro y desencuentro entre ellas, y menos importancia al principio configurador en cuanto tal. En este sentido, la hermenéutica foucaultiana al reducir sus análisis a la configuración de una complejidad, o mejor, a la articulación de varios horizontes discursivos, es rica en flexibilidad como es enormemente rica en su poder de impacto y seducción hermenéutico, precisamente, con la misma versatilidad con la que no se permite identificación alguna con un sujeto, causa o idea.

Por consiguiente, el principio configurador como tal queda reducido con Foucault a un puro poder de enebramiento, más que a desencubrir su poder configurador, sin una verdadera articulación a un orden de complejidad en el cual encontremos su verdad última . Sin la idea de la vida como protagonista, sin esa cercanía al darwinismo fisiológico del que no por mera ósmosis científica el autor del Zaratustra hizo uno de sus baluartes; sin esa reflexión sobre la vida, la genealogía de Nietzsche carecería de esa ley interna que unas veces da sistematicidad a su filosofía y otras la despedaza en miles de retazos de crítica histórica, cuando no se hace manifiesta y sucumbe a los poderes misteriosos del ocultamiento con los que gusta vestirla y revestirla su autor. En pocas palabras: sin la referencia a la vida como el indiscriminado ejercicio de la fuerza, la genealogía nietzscheana habría pecado de inconsistencia.

A pesar de que esta idea pareciera intentar pedirle a la filosofía de Nietzsche precisamente aquello que carece, (en cuanto que ella elude concientemente la calificación de sistema), por lo pronto, la ausencia de una respuesta a la cuestión de la vida en la genealogía foucaultiana nos permitirá, al menos por el momento, considerar sus diferencias con la teoría del poder de Foucault.

Para exigir que el hombre funde su credibilidad como hombre, para educar al hombre como hombre de confianza, la moral occidental como moral cristiana ha intentado marcar con fuego y sangre un estilo, una figura específica, una mentalidad, un hombre moral a costa de su propia libertad y de su propia dignidad como hombre. El hombre de las promesas nace del dolor y del encarcelamiento de sus capacidades más sublimes, o mejor, es un producto de sus maquinaciones mediante la introyección de la culpa, mediante la eliminación de las incertidumbres, mediante la castración 
del olvido. Con el triunfo de la memoria sobre el olvido y la inseguridad que esta conlleva, el hombre moral, el hombre culpable, sucumbe a las virtudes castrantes del rebaño. Sin embargo, el poder de ejercer esta corrección del mundo, como castración de la vida, va mucho más allá de una mera constatación neutral del hermeneuta, de una supuesta asepsia de sujetos y estructuras, puesto que obedece, como quiere Nietzsche, a la violencia que la vida y la voluntad de poder ejerce necesariamente como infinito acrecentamiento de la fuerza.

En este caso, en Vigilar y Castigar la ausencia del origen del poder, la ausencia de la vida como principio configurador del poder o de la fuerza, nos permite observar una excesiva positividad de sus denuncias, que al abandonar su origen pierden su contextura histórica para devenir realidad sin principio aparente, sin referencia inmediata, divorciada del rol activo de la capacidad creativa de los hombres, huérfana de una estructura en la que nos permitiéramos encontrar su verdadero principio configurador.

El poder es capaz de castigar para configurar el orden social que necesita, mediante una vertebración en todos los fenómenos sociales, científicos y culturales, tan exento de origen como pleno de positividades. El castigo, en este caso, solo se manifiesta como una función social compleja, más allá de su poder represivo o punitivo, solo en su carácter de articulación a otros procedimientos, más no a su sentido estrictamente negativo o a su carácter represivo como tal. El castigo como articulación del poder no nos muestra más que su cara positiva, haciendo manifiesta, en primer y único lugar, su articulación a otros fenómenos tan positivos y constatables como éstos.

Al desprenderse de la ilusión de que la penalidad es pura represión, Foucault intenta articular todo el devenir social y discursivo del poder en la modernidad, refiriéndolo a su vertebración en instancias ajenas o alejadas de los horizontes que tradicionalmente se han consignado al ejercicio del poder, donde se hace manifiesta una totalización configuradora marginal al poder y/o incorporándolo en su mismo devenir, en la que no podemos observar más que las positividades o decantaciones reales, las efectividades del poder en el devenir social. Lo único que se puede llegar a observar aquí, debido al abandono consciente de una estructura de sustento, es la capacidad articuladora de la vis social que se manifiesta en una serie de efectos positivos y útiles, a los que tiene por misión sostener, los que en sí mismos están divorciados de las actividades concretas y cotidianas de la vida social, como, al mismo tiempo, son fieles representantes de una enajenación o de una incapacidad de la razón para atrapar a la sensibilidad y lo concreto, en una palabra: mera positividad.

Tanto la lucha de Foucault contra el estructuralismo y las continuidades de la historia de las ideas y del materialismo histórico, como las críticas de Nietzsche a los excesos de la interpretación histórica en la segunda de sus Consideraciones Intempestivas parecen, aparentemente, situarlos en un mismo horizonte hermenéutico, asunto que si analizamos bien, no resulta igual.

Cuando Nietzsche dirige su crítica a la filosofía historicista de Hegel y Hartmann, y a El origen de los sentimientos morales (1877) de su amigo Paul Rée, lo hace en nombre de la vida, es decir, pretende desencubrir su determinis- mo apelando al radical indeterminismo de la vida. Por el contrario, en Foucault y su polémica contra el historicismo no encontramos más que la idea de la superación de las estructuras y del sujeto, en provecho de una genealogía que carece de principio nutricio, que oculta en el estado de conjunto y en el encadenamiento a un principio o red que atraviesa todo el cuerpo social, el valor puramente nominal de los orígenes.

Al intentar pensar las leyes que rigen a la historia y sus diversas articulaciones, sin referencia a un sujeto ni a una estructura de sustento, salta a la vista el carácter de pura obsesión con los nudos de una red, mas que al intento por descubrir las virtudes articuladoras del tejedor. Como vemos, el carácter ilusorio de esta crítica histórica salta a la vista, pues su existencia real queda suspendida en un sistema de remisiones que solo adquieren consistencia en la continuidad y ruptura de su enebramiento. De ahí la necesidad de que la prioridad de la genealogía foucaultiana esté en desenmascarar la positividad de las articulaciones, es decir, en cómo es posible comprender que los fenómenos sociales en general, como los fenómenos del poder en especial, son susceptibles de análisis en cuanto a su exclusivo poder de articulación positivo, sea en su condicionamientos más inmediatos, como sea desde el punto de vista de articulaciones marginales o de horizontes aparentemente ajenos a los fenómenos analizados.

Es claro que la capacidad hermenéutica crece en complejidad cuando es capaz de descentrar el análisis de los elementos tradicionales y de los orígenes consignados por las tradiciones, para dar cabida a formas de articulación insospechadas. También es evidente que siguiendo una vía paralela a la tradicional y sin abandonarla completamente, la vía sin sujeto y sin estructuras de la historia, da cabida a nuevas formas de articulación, que en parte, y muy a pesar de lo novedoso que puedan aportar en el análisis, ya se sospechaban como posibles articulaciones. En este caso, las sorpresas, rupturas y distanciamiento deben, por consiguiente, saltar a la vista. No obstante, el énfasis en el juego de las remisiones no es más que el producto de la eliminación de la procedencia y de todo origen, es decir, su virtud simuladora, su inconsistencia, pues al desprenderse de todo referente, parece autorizada a vincularlo todo precisamente por su desprendimiento inicial.

Vigilar y castigar es, por este motivo, no sólo una desarticulación de las instancias tradicionales del poder, y en este sentido, una perplejidad total o una simulación generalizada, como piensa Baudrillard; sino también, representa una nueva forma de comprender las articulaciones del poder más allá o más acá de un único horizonte de procedencia. Es esta multivocidad del poder lo que más sorprende del análisis foucaultiano, a pesar de cierta condescendencia con la generalización, a pesar de su encanto con las argumentaciones que muchas veces carecen de verdaderos sustentos, (por lo general, cuando se ven reducidos a meras enumeraciones) debido, precisamente, a la necesidad hermenéutica de prescindir de todo horizonte condicionante que no sea más que la totalidad social o el efecto de conjunto.

De Nietzsche, Foucault hereda la intención del desenmascaramiento de la modernidad, en los términos de una violencia interpretativa, como también el intento de repensar el pasado que nos enseña la historia, sobre la base de un 
verdadero distanciamiento de la hermenéutica tradicional al poner en entredicho el valor de la verdad. Sin embargo, cuando Nietzsche descubre las razones de la crueldad y de la voluntad del hacer sufrir como manifestaciones de la voluntad de poder y de la vida, es decir, cuando descubre a la violencia como el trasfondo de toda cultura, nos permite comprender que su violencia interpretativa articula la crítica en lo criticado, de tal manera que éste no permanece ajeno a aquel.

Como ejercicio del poder de quienes intentan hacer memorizar a los demás una historia y un concepto de la vida, el arte del suplicio, además de significar una manifestación del poder, como quiere Foucault, es la manifestación de una propiedad normal entre los hombres, pues hacer sufrir provoca un sentimiento de bienestar y es un derecho de los que dominan.

Como vemos, la idea de la vida como articuladora de la crueldad y del poder no es ajena al poder del castigo, ni menos al ejercicio del poder en general; es parte fundamental de ella misma.

Para Foucault, el suplicio es la manifestación del poder de castigar del soberano o la memoria que el soberano quiere imponer a sangre y fuego en el pueblo, mediante la libre determinación de su voluntad de permitir o no permitir la vida de sus súbditos. A pesar de la insistencia de Foucault por señalar el carácter coextensivo del poder en todo el cuerpo social, resulta que siempre termina por encadenar su ejercicio a lugares comunes (las clases sociales y su poder o las distintas discursividades o epistemes que configuran al cuerpo social), cuidándose, como es el caso, de no caer en los conceptos de la interpretación histórica tradicional. Con este intento de concebir al poder de modo indeterminista, Foucault no quiere asignarle a éste, como era de esperar, un lugar específico en la sociedad, ya que no es parte ni de una estructura de la sociedad, ni es producto del ejercicio de una clase social, sino es una red productiva que atraviesa todo el cuerpo social. Es claro, por lo demás, que la elusión consciente de un origen determinado no solo le da una mayor extensión al concepto del poder, sino también anula o elimina su carácter universal, en la medida en que al afirmar constantemente su carácter articulador, termina supeditado a representar una diversidad de prácticas, tanto más vagas como indeterminadas en sí mismas.

Bien que esta afirmación nos pueda parecer contraria a nuestras intenciones argumentativas, (si pensáramos en el valor de la extensión del concepto del poder como aporte de Foucault a la investigación filosófica), lo cierto es que Nietzsche al conducirnos al seno de la idea de culpa, nos recuerda que la más antigua y originaria forma de relación entre los hombres estuvo cargada de ese sentido de batalla perpetua entre acreedores y deudores, de ese sentido vital de infinita voluntad de dominio que en última instancia queda relegada al olvido cuando se la categoriza en una voluntad de conciliación, abandonando la voluntad propia y el ser la medida del valor tal como sucede entre los hombres libres. Como vemos, al situar Nietzsche el seno de la vida social en la batalla perpetua entre acreedores y deudores, no hace más que pensarla desde la voluntad de dominio, la misma que estando en la base de la vida individual y social de los hombres, tal como lo describe el sentimiento vital que da sustento a la filosofía política y moral griega, la vemos claramen- te representada en la Ética Nicomaquea de Aristóteles (Libros VI y IX ), cuando declara que la voluntad de dominio es el impulso vital que está presente tanto en el seno de las relaciones sociales y en la configuración del yo, como en la amistad y las relaciones amorosas.

Como vemos, Nietzsche ve al poder como ejercicio de la vida, ya que si desconocemos la esencia de la vida desconocemos su voluntad de poder y con ello pasamos por alto la supremacía del principio que poseen las fuerzas espontáneas, agresivas, invasoras, creadoras de nuevas interpretaciones, de nuevas direcciones y formas, por influjo de las cuales viene luego la adaptación. (Genealogía de la Moral. Federico Nietzsche. Alianza Ed. pág 90). Es claro, para nosotros, que Nietzsche dirige aquí una crítica a todos los ingenuos genealogistas de la moral y del derecho (sic !), quienes no son capaces de comprender el ejercicio del poder y sus más diversas configuraciones, como manifestaciones de la fuerza constructora y destructora de la vida .

La crueldad, el dolor y las guerras son tan viejas como la vida en la tierra. El hecho que existan y sigan existiendo significa que la voluntad de saber y la voluntad de poder además de ser una y la misma realidad, deben ser concebidas como fuerzas articuladoras del poder, es decir, como manifestaciones de la vida en la infinita búsqueda del acrecentamiento de la fuerza, en la infinita configuración del devenir a su medida, mediante la creación de valores como medios para el acrecentamiento de sí misma. En este sentido, la genealogía de Rée y de los genealogistas ingleses, le parecieron a Nietzsche una magistral elusión de lo verdadero que hay en toda vivencia moral, en cuanto en ellas no vemos más que una representación de algo que en cuanto fuerza irreversible que crea y recrea sus propias condiciones de acrecentamiento se oculta, debiendo contentarnos con una idea altruista de la valoración, con una representación de la vida, más que con la vida misma, tal como a Nietzsche le parece la idea de la moral de la compasión. Al abandonar el sentido vital de ella para entregarla a los lugares comunes de una abnegación que más que representar a la vida es una máscara de ella, al abandonar la moral a un orden puramente representativo, en una palabra, al someter a la idea central de la compasión como vertebración de la moral y su historia, el valor de la compasión se confundía con una comprensión de la vida, como algo dado, real y efectivo, situado más alla de toda duda.

Pero tras esa realidad subyacía toda una tradición de prejuicios, de miedos y de desesperanzas que hacían más difícil su verdadera comprensión. En definitiva, la valoración compasiva era una introyección de una idea completamente débil de la vida, una interiorización de aquello que en sí mismo era la negación de ella.

Según este balance crítico de las valoraciones morales, la referencia a la vida es una condición sine qua non de la genealogía de la moral, so pena de verse llevada por las valoraciones que la vida hace de sí misma o por el grado de vitalidad que ella represente, hacia un horizonte en el que ella misma se confunda con su representación. Como vemos, Nietzsche nos enseña a situar al problema de la moral y del derecho en un orden vital, el que por su manifestación en todo orden de cosas, por su extensión a todos los casos, aparece más como positividad, como vertebración de positividades, que como fuerza configuradora de la diversidad. 
De ahí la afición genealógica de reconocer en ellos, en las positividades, como un verdadero error, la mera representación de la vida y no su esencia.

Con esta afición por comprender las exterioridades del poder se inicia la genealogía foucaultiana, la que a nivel de la representación de la vida, considera la manifestación del suplicio público en su engarce con el ámbito de la verdad, pues la manifestación objetiva del dolor corresponde a la marca que impone con sangre y fuego el soberano en la memoria colectiva del pueblo, mediante el sinuoso y secreto construir de la penalidad que no necesita más que de una acusación o de una forma mecánica de producir la verdad en la sentencia. El cuerpo del torturado en la plaza pública es la representación del poder de incorporación de la verdad en el pueblo, la teatralización del reto físico en el juicio o en la sentencia que certifica la verdad. Para Foucault el cuerpo del torturado es el lugar de consolidación de la verdad.

En este sentido, los dispositivos del poder no proceden ni por represión ni por ideología, pues el poder normaliza porque disciplina y disciplina por que normaliza. Pero frente a la normalización del suplicio público, Foucault advierte el desencuentro y la ruptura por su propio crecimiento indiscriminado, por su propia capacidad de volverse real, obvio y manifiesto, por su propio poder de representación y sobreexposición en lo real.

La ley de caducidad del poder que se hace manifiesta aquí, a través de su capacidad de normalizarse en la realidad o de ser una representación de una representación, no parece ser otra que la que declara su propia volatilización cuanto más representación de sí misma se vuelve. Cuando esto sucede, cuando el poder sucumbe a su propia capacidad de articulación, nace el contra-poder, nacen los ilegalismos. La ley interna que parece regir el análisis del poder y de la punición en el mundo moderno, al menos en la versión foucaultiana, no está lejos de ser una constante crisis de normalización representativa, debido al exceso de ordenación y normalización de la realidad a la que ella tiende, puesto que la dialéctica del poder encuentra sus límites en el mismo exceso de positivización que la empuja. Cuando este proceso llega a su extremo, sucumbe en la ilegalidad o en la necesidad de una reprogramación cada vez más exhaustiva de su poder de normalización, pues sucumbe en la necesidad de una economía del poder que sea capaz de retroalimentar su capacidad ordenadora y disciplinaria con la absorción de cada vez más realidad (jurídica, social, educativa y cultural) en su poder de contrición normalizadora.

A pesar de eludir las interpretaciones tradicionales sobre la crítica de la Ilustración para acabar con todo tipo de barbarismos y con los excesos de la irracionalidad punitiva, más bien, Foucault considera que la Ilustración al estar sometida al poder de sistematización y articulación que comanda el dispositivo de producción de la verdad, no sirve más que para consolidar aún más el poder de normalización de la verdad mediante estrategias de reajuste y control cada vez más funcionales, cada vez más articuladas a la defensa de la sociedad y del orden social. Por ello que, frente a la crisis del poder del soberano, la reforma penal de los ideólogos de finales del siglo XVIII, no parece más que hacer manifiesta esa necesidad de autorregulación constante del poder, a través de la absorción paulatina de todos los horizontes con los cuales se permita consolidar la construcción de una racionalidad cada vez más funcional y económica.
Aparentemente, el cuerpo en la reforma de finales del siglo XVIII queda sometido a la representación, pues la reforma de la penalización del delito buscó prevenir el desorden social a través de la representación y teatralización de las penas, sea como publicación y difusión de los códigos penales, sea como verificación de su eficacia mediante su anexión a los criterios más generales de la verdad, pues de lo que se trataba era de irrumpir en la subjetividad individual del delito, buscando la prevención representadora de la pena y el castigo, como ingreso a una época marcada por la sobriedad punitiva, por la introyección de la pena en la subjetividad culposa de los individuos.

No obstante que esta hermenéutica del arte de castigar estuvo marcada por ese instinto de sobriedad reglamentadora, (sobre todo, como benignidad de las penas), en cuanto buscó alcanzar una economía punitiva cada vez más rigurosa, al mismo tiempo, este factor le permitió superarse infinitamente debido a su constante entropía en la positivización o en la dinámica de la desreglamentación y reglamentación. Sin embargo, lo cierto es que la ley de la introyección de la culpa, como ley interna de la vida, no parece obedecer a los propósitos de una depuración representadora, ni menos a la dinámica interna de una suerte de crisis de positivización constante, sino más bien a la fuerza inhibidora de la vida que vista la interrupción de sus instintos se vuelve contra sí misma.

No es una mera coincidencia que tanto Nietzsche como Foucault traten con minucioso detenimiento el problema de la interiorización de la violencia en el alma individual como el fenómeno del ilegalismo del poder, pero bajo una luz completamente diferente.

Cuando el poder se acreciente, dice Nietzsche, crece la tolerancia y se inicia una impunidad generalizada: Si el poder y la autoconciencia de una comunidad crecen, entonces el derecho penal se suaviza también. Con la conciencia de plenitud del poder se hace manifiesta una laxitud en la búsqueda de más poder, dirigiéndose esta última, como mero desahogo, a la condonación de las penas, a la impunidad y tolerancia con respecto a lo que en otro tiempo era delito, por cuanto en ella ocupa la energía que no ha gastado en la búsqueda de más poder.

Como podemos apreciar aquí, la laxitud del poder también es un fenómeno de generación de la ilegalidad, por cuanto en la ilegalidad el poder, en el caso del señorio de los más fuertes, se solaza de su poderío en la laxitud de una aparente inconsistencia.

Muy por el contrario, en Vigilar y castigar Foucault nos muestra que la tolerancia de las ilegalidades empuja a una economía más severa del poder de castigar, incluso en el caso de la idea de la penalidad como prevención del delito, según consideraron los reformadores de la penalidad y el delito a finales del siglo XIX. Pero la economía de los ilegalismos no obedece única y exclusivamente a los cambios en la forma de reproducción del poder (como quisiera el materialismo histórico), ni exclusivamente al poder de contrición que ejecutan las ciencias humanas desde inicios del siglo XIX como mecanismos normalizadores de la verdad mediante la confesión, sino al engarzamiento de todos esos factores como efecto de conjunto.

En este orden de cosas, el efecto de conjunto representa, más bien, la fe en que en el aislamiento y fijación de las de- 
terminidades y en la profundización de una sola realidad como si fuera la esencia de la relación, se pretenda encontrar el principio de articulación de lo real. Más bien, mediante el criterio de la referencia positiva, la realidad queda reducida a su contenido formal o meramente empírico, escapándosele lo real en una pura apariencia de necesidad, vale decir, en la mera representación formal. Una de las pocas veces que Foucault define al poder, lo hace de modo negativo ( $₫$ o elusivo?): el poder no es ni una institución, ni una estructura, ni una fuerza --- es el nombre que se da a una situación estratégica compleja en una sociedad dada. En esta aproximación al poder, observamos ese aire distribucional y vectorial, como dice Baudrillard, en el que una expansión infinita parece amenazar la universalidad del concepto, hasta volatilizarlo completamente en una connotación sin referente alguno.

Pero no debemos sospechar de esta ausencia de realidad en el análisis del poder más que cuando consideremos que en la historia de la filosofía moderna se da una suerte de ley oculta, puesto que cuanto más ausente está la vida en ella, tanto más busca enclaustrarse a sí misma en la representación, de tal modo que, como si obedeciera a una misteriosa necesidad, su ausencia no es más que la viva representación de sí misma.

Con esta nueva filosofía del poder, con esta nueva escritura del poder, que no por el simple hecho de ser demasiado bella tiene que necesariamente ser verdadera, la genealogía de Nietzsche aparece en ese fondo insospechado que estuvo presente en todos aquellos reclamos que se le hizo a la filosofía después de Kant, cuestión que no solo se manifestó como un acalorado debate por recuperar a la vida, sino, antes bien, como una lucha tenaz por separar a la filosofía del positivismo, para liberarla del pensar calculador.

No es por mero acostumbramiento que hoy en día, a pesar del positivismo reciclado en la sustentabilidad, la defensa de la vida no refleje más que el intento de dar coherencia a los triunfos de la especialización científica. Por lo pronto, y en este sentido, dejemos que el encuentro entre Nietzsche y Foucault nos dé qué pensar. 


\section{Marena Briones Velastegú}

Entre la muerte y la vida

\section{Byron SIIVA}

Eutanasia: Felici vel honesta morte mori

Fabián Corral B.

Las dimensiones éticas de lo público 